\title{
Evaluation of Potato Genotypes for Foliar and Tuber Resistance against Phytophthora infestans Causing Late Blight of Potato under Subtropical Plains of India
}

\author{
Mehi Lal,, S.K. Luthra, V.K. Gupta and Saurabh Yadav \\ ICAR-Central Potato Research Institute, Regional Station, Modipuram 250110, \\ Uttar Pradesh, India \\ *Corresponding author
}

\section{Keywords}

Foliar, Tuber, Resistance, Late blight and Potato

Article Info

Accepted:

10 February 2018 Available Online: 10 March 2018

A B S T R A C T

The late blight disease caused by Phytophthora infestans, is a serious threat to potato cultivation worldwide. The varietal resistant is cheapest and environment friendly for management of this disease. A total of twenty two (two sets) advanced potato hybrids along with four control varieties namely Kufri Bahar, Kufri Garima, Kufri Shailja and Kufri Girdhari were evaluated during crop seasons (2012-15) for resistance against late blight. In set 1 , based on field evaluation result revealed that advanced hybrid MS/9-723 showed highly resistant AUDPC (45.38), another hybrid MP/04-578 showed AUDPC (82.00) was resistant and 7 hybrids showed AUDPC (150-375) were moderately resistant and remaining two were susceptible (>375) against cv. Kufri Bahar (AUDPC-925.00) during 2012-14. In set 2, two advanced hybrids viz, MS/10-885 (75.46) and MP/07-214 (13.00) were highly resistant, MS/10-966 (77.31) was resistant and remaining 8 hybrids were moderately resistant during 2013-15 against cv. Kufri Bahar (AUDPC-749.34). In laboratory test, in set 1; five hybrids were moderately resistant and remaining were susceptible for foliar while three hybrids were moderately resistant and reaming were susceptible for tuber resistance. Similarly, in set 2, three hybrids were resistant, six were moderately resistant and two were susceptible foliar infection while two were resistant and remaining hybrids susceptible for tuber resistance. Foliage resistance, tested under laboratory condition using detached leaf test and field condition did not establish close relationship. The expression of late blight in foliage and tuber were not closely related.

\section{Introduction}

The oomycete pathogen Phytophthora infestans (Mont.) de Bary, is still an important pathogen of the potato and tomato crops after more than one hundreds seventy years of occurrence of late blight epidemic in Ireland. The late blight is one of the most destructive diseases of potato and results in yield losses up to $95 \%$ in epidemic conditions. In India, it cause up to $10-15 \%$ yield loss of potato on over all basis (Lal et al., 2016). The yield loss caused by $P$. infestans, can be minimized using host resistance, chemicals, forecasting, sanitation and even disease escape (Wastie, 1991). Host resistance had always been a better option than the fungicides, since these are expensive, environmentally hazardous and pathogen 
develops resistance to the fungicides over a period of time. Moreover, at elevated temperature fungicides may degrades and its effectiveness could be reduced against late blight of potato (Yadav et al., 2016). A conservative estimate for management of late blight of potato is about 6.7 billion dollar at worldwide ( $\mathrm{Hu}$ et al., 2012). As awareness of environmentalist and consumers, it will be better to reduce the use chemicals as a long term strategies. So that we can produce potatoes with a prescribed limit of the fungicides residues or fungicides free. The resistance is governed by mono and polygenic inheritance. It will be always better if we could develop a variety with polygenic inheritance. Because it has resistance to may genes that could counteract against many races of $P$. infestans. Host resistance in late blight can be of two types i.e. foliage and tuber resistance.

Foliar resistance gives better protection in the field and reduced the chances of yield losses under epidemic condition while tuber resistance is minimized to get infection of the tubers. So that next year as a source of the primary inoculum is less chance and also reduces the losses under storage condition. Moreover, an estimated economic losses > 1 to 3 million dollars were reported in past years, due to tuber rot caused by $P$. infestans in storage facilities in the Columbia Basin of Washington and Oregon (Johnson et al., 2000). $P$. infestans is polycyclic in nature and completes many cycles in a crop season (Agrios, 2006). It changes its pathogenic behavior, forms new race complexes and adapts to new environment very soon.

Consequently, host resistance of a variety is run down over the years due to appearance of matching virulent races. Therefore, it is essential to continuously evaluate wide range of genotypes against $P$. infestans for both tuber and foliage resistance.

\section{Materials and Methods}

\section{Foliage resistance in field}

A total of twenty two (two sets of hybrids, 11 in each set) advanced potato hybrids along with four control varieties namely Kufri Bahar (Highly susceptible), Kufri Garima (Moderately resistant), Kufri Shailja (Moderately resistant) and Kufri Girdhari (Highly resistant) were evaluated during crop seasons (2012-13 \& 2013-14; 2013-14 \& 2014-15) for late blight resistance at ICAR-Central Potato Research Institute, Regional Station, Modipuram Meerut $\left(29.1^{\circ} \mathrm{N}, 77.92^{\circ} \mathrm{E}, 300\right.$ masl). The genotypes were planted in the first week of November every year in the plot size of $3 \mathrm{x}$ $3 \mathrm{~m}^{2}$ keeping $60 \times 20 \mathrm{~cm}$ row plant distances using three replications for each genotype. The crop was raised following the standard agronomic practices $(180 \mathrm{~N}-80 \mathrm{P}-100 \mathrm{~K} / \mathrm{ha})$ of the regions without any application of fungicides. The artificial inoculation of $P$. infestans (zoospore suspension $6 \times 10^{4}-1 \mathrm{ml}$ ) was done in infector rows for initiation and spread of disease. The sprinkler system was installed at field and initially minimum two times's sprinkled the crop in a day for maintaining proper congenial condition of disease development and spread. Disease severity was recorded at regular interval according to Henfling, 1987, after appearance of the disease on the Kufri Bahar (Highly susceptible) till it was completely killed. Disease severity was converted into area under disease progress curve (AUDPC) according to Shanner and Finney, (1977). The relative AUDPC (rAUDPC) were also calculated as per Perez and Forbes, (2010).

\section{Foliage resistance in lab with detached leaf test}

For evaluation of foliage resistance to late blight in laboratory, fourth leaf from the top of plant was plucked from each genotype and 
challenge inoculated with $P$. infestans (Mating type A1, Metalaxyl resistant, Race1 2.3.4.5.6.7.8.9.10.11) using filter-paper discs $\left(0.3 \mathrm{~cm}^{2}\right)$ pre-dipped into the zoospore suspension (6 x 104 $-1 \mathrm{ml}$ ). The inoculated leaves with five replications for each genotype were incubated at $18 \pm 1^{\circ} \mathrm{C}$ and $85 \% \mathrm{RH}$ in growth chamber for five days and lesion area was measured (Singh and Bhattacharyya, 1995). The genotypes were grouped based on lesion area $\left(\mathrm{cm}^{2}\right)$ : up to 1.0 - Highly resistant (HR); 1.1 to 2.5- Resistant (R); 2.51-5.0Moderately resistant (MR); and > $5.0-$ Susceptible (S) according to Singh (2002).

Tuber resistance in lab with tuber slice method

For estimation of tuber resistance, tubers of genotypes were tested after harvesting using tuber slice method, In this method tubers were initially surface sterilized with ethyl alcohol (95\%.con) followed by cutting the thick slices $(1.0 \mathrm{~cm})$ aseptically after that each genotype were challenge inoculated with $P$. infestans (Mating type A1, Race1.2.3.4.5.6.7.8.9.10.11) using filter-paper discs $\left(0.3 \mathrm{~cm}^{2}\right)$ pre-dipped into the zoospore suspension $\left(6 \times 10^{4}-1 \mathrm{ml}\right)$.

The inoculated tuber slice with three replications for each genotype were incubated at $18 \pm 1^{\circ} \mathrm{c}$ and $85 \% \mathrm{RH}$ in growth chamber for five days and lesion area was measured.

The lesion area $\left(\mathrm{cm}^{2}\right)$ was measured and the genotypes were grouped into highly resistant (up to 1.0), resistant (1.1-2.5), moderately resistant (2.51-6.0) and susceptible (>6.0). Corelation coefficient between AUDPC and rAUDPC, AUDPC and detached leaf, AUDPC and tuber resistance, detached leaf and tuber resistance were also calculated.

The experimental data were analyzed with the help of IRRISTAT software (version 4.4.20030719).

\section{Results and Discussion}

\section{Foliage resistance in field}

The results revealed that advanced potato hybrids showed different levels of resistance to $P$. infestans. In set 1 , all advanced hybrids showed less AUDPC compared to highly susceptible cv Kufri Bahar. On the basis of mean (2012-14) data, minimum AUDPC was recorded in MS/9-723 (45.38) and highest was in MS/8-861 (401.88) as against cv. Kufri Bahar (925.00), Kufri Garima (411.97), Kufri Shailja (173.71) and Kufri Girdhari (18.77). Therefore, advanced hybrid MS/9-723 was graded highly resistant (AUDPC up to 75). One advanced hybrid i.e. MP/04-578 was resistant (AUDPC 75.10 to 150) and 8 advanced hybrids (AUDPC 150.10 to 375 ) were moderately resistant, while remaining 1 advanced hybrid (AUDPC > 375) was susceptible (Table 1). Similarly, in set 2; minimum AUDPC was recorded in MP/07214 (13.00) and highest was in MCIP/09-01 (332.56) as against cv. Kufri Bahar (749.34), Kufri Garima (328.64), Kufri Girdhari (13.98) and Kufri Shailja (128.50) during 2013-15.

Therefore, advanced hybrid i.e. MP/07-214 was graded highly resistant (AUDPC up to 75). Two advanced hybrids i.e. MS/10-885 \& MS/10-966 were resistant (AUDPC 75.10 to 150) and remaining hybrids (AUDPC 150.10 to 375 ) were moderately resistant (Table 2). In set 1 , the mean rAUDPC values of tested advanced stage hybrids during 2012-14, ranged from 0.03 to 0.26 (Table 1) as against highly susceptible cultivar Kufri Bahar (0.60) and known late blight resistant varieties i.e. $\mathrm{K}$. Kufri Girdhari (0.01) and Kufri Shailja (0.12), whereas in set 2 , the mean rAUDPC values of tested advanced stage hybrids during 2013-15, ranged from 0.01 to 0.22 (Table 2) as against highly susceptible cultivar Kufri Bahar (0.49) and known late blight resistant varieties i.e. Kufri Girdhari (0.01) and Kufri Shailja (0.09). 
Foliage resistance in lab with detached leaf test

The results of detached leaf test showed that none of the advanced hybrids was highly resistant in set 1 during 2012-14, whereas five advanced hybrids i.e. MS/8-88, MS/8-861, MS/9-723, MS/9-2185 and MP/04-816 were moderately resistant (lesion area between 2.51 and $5.0 \mathrm{~cm}^{2}$ ).

The remaining 6 advanced hybrids along with control cv. Kufri Bahar with lesion area more than $5.0 \mathrm{~cm}^{2}$ were susceptible (S) to late blight (Table 1). Similarly, in set 2; the results of detached leaf test showed that none of the advanced hybrids was highly resistant during 2013-15.

The advanced hybrids MS/10-940, MCIP/0911 and MCIP/09-12 were resistant, whereas 6 advanced hybrids i.e. MS/10-927, MS/101529, MCIP/09-01, MP/06-39, MP/07-214 and HT/10-2505 were moderately resistant (lesion area between 2.51 to $5.0 \mathrm{~cm}^{2}$ ). The remaining two advanced hybrids along with control cv. Kufri Bahar with lesion area more than $5.0 \mathrm{~cm}^{2}$ were susceptible (S) to late blight (Table 2).

A lower AUDPC value indicates higher level of resistance. Low values of rAUDPC have low infection level during the period of evaluation and therefore correspond to more resistant varieties (Perez and Forbes, 2010; Lal et al., 2013).

Foliage resistance tested under laboratory and field conditions did not establish a close relation because in laboratory, ideal temperature and humidity was maintained with a fixed amount of inoculums load, while in field conditions, inoculums load and weather may be variable. Under field condition one year may be extreme humidity due to high rainfall, while in other year may be low humidity due to existing weather conditions. Singh and Birhman (1994) developed a technique for laboratory estimation of field resistance to late blight for screening of resistant genotypes. However, they reported that the ranking of the genotypes with almost similar level of resistance in laboratory was not exactly the same as obtained in the field.

Knutson (1962) also reported that the expression of non-specific resistance of the leaves of the three cultivars grown in a glasshouse was closely related to that of field grown plants, however one cultivar was resistant to blight when grown in a glass house but susceptible in the fields. Limitation of greenhouse screening is that the controlled environment may not adequately mimic the complexities of a field trial.

Consequently, level of resistance may not correlate strongly with the greenhouse (Simko et al., 2007). In present study the resistant advanced hybrids were less under laboratory test than the field condition. Similar observation also observed by Kaushik et al., (2007) that the numbers of resistant accessions were less in detached leaf test because the most complex race was used in challenge inoculation and inoculums load was also high compared to field conditions Greenhouse and laboratory assays cannot replace the value of evaluating germplasm for foliar resistance to late blight under field conditions (Dorrance and Iglis, 1997). Under field condition, the hybrids are exposed against $P$. infestans in natural environment with all existing climatic factors (temperature, humidity, light and precipitation etc.) and hybrids tries to fend off from pathogen attack while pathogen tries to dominate on the hybrids. Therefore, no substitute is available to replace field evaluation with laboratory/green house for evaluation of hybrids against late blight. However, laboratory results may be taken as initial information in the form of resistance. 
Table.1 Foliar and tuber resistance of advanced stage hybrids in set 1 during 2012-2014

\begin{tabular}{|c|c|c|c|c|c|c|c|c|c|c|c|c|c|c|c|}
\hline \multirow[t]{3}{*}{ S.N. } & \multirow[t]{3}{*}{ Hybrids } & \multicolumn{6}{|c|}{ Foliage resistance in field } & \multicolumn{4}{|c|}{ Foliage resistance in Lab } & \multicolumn{4}{|c|}{ Tuber resistance in Lab } \\
\hline & & \multicolumn{2}{|c|}{ *AUDPC } & \multirow[t]{2}{*}{ Mean } & \multicolumn{2}{|c|}{ *rAUDPC } & \multirow[t]{2}{*}{ Mean } & \multicolumn{2}{|c|}{$\begin{array}{l}\text { Detached leaf lesion } \\
\qquad \operatorname{area}\left(\mathrm{cm}^{2}\right)\end{array}$} & \multirow[t]{2}{*}{ Mean } & \multirow[t]{2}{*}{ Grade } & \multicolumn{2}{|c|}{$\begin{array}{c}\text { Tuber slice lesion } \\
\operatorname{area}\left(\mathrm{cm}^{2}\right)\end{array}$} & \multirow[t]{2}{*}{ Mean } & \multirow[t]{2}{*}{ Grade } \\
\hline & & 2012-13 & 2013-14 & & 2012-13 & 2013-14 & & 2012-13 & 2013-14 & & & 2012-13 & 2013-14 & & \\
\hline 1 & $\mathrm{MS} / 8-88$ & 217.00 & 371.33 & 294.17 & 0.14 & 0.25 & 0.20 & 4.16 & 4.13 & 4.15 & MR & 4.76 & 8.24 & 6.50 & $\mathrm{~S}$ \\
\hline 2 & MS/8-861 & 480.00 & 323.75 & 401.88 & 0.30 & 0.22 & 0.26 & 4.78 & 2.81 & 3.80 & MR & 3.71 & 5.79 & 4.75 & MR \\
\hline 3 & MS/9-723 & 52.00 & 38.75 & 45.38 & 0.03 & 0.03 & 0.03 & 6.33 & 3.31 & 4.82 & MR & 9.55 & 10.12 & 9.84 & S \\
\hline 4 & MS/9-912 & 290.00 & 374.38 & 332.19 & 0.18 & 0.25 & 0.22 & 7.88 & 5.89 & 6.89 & $\mathrm{~S}$ & 5.39 & 6.51 & 5.95 & MR \\
\hline 5 & MS/9-1061 & 252.00 & 359.58 & 305.79 & 0.16 & 0.24 & 0.20 & 5.49 & 5.05 & 5.27 & $\mathrm{~S}$ & 7.06 & 11.77 & 9.42 & S \\
\hline 6 & MS/9-1083 & 382.00 & 293.5 & 337.75 & 0.24 & 0.20 & 0.22 & 6.39 & 5.02 & 5.71 & $\mathrm{~S}$ & 9.80 & 7.07 & 8.44 & $\mathrm{~S}$ \\
\hline 7 & MS/9-2185 & 388.00 & 351.83 & 369.92 & 0.24 & 0.24 & 0.24 & 5.15 & 4.06 & 4.61 & MR & 9.17 & 14.45 & 11.81 & S \\
\hline 8 & MP/04-578 & 82.00 & - & 82.00 & 0.05 & - & 0.05 & 6.44 & - & 6.44 & $\mathrm{~S}$ & - & - & - & - \\
\hline 9 & MP/04-816 & 240.00 & - & 240.00 & 0.15 & - & 0.15 & 4.09 & - & 4.09 & MR & 2.57 & - & 2.57 & MR \\
\hline 10 & MP/08-60 & 362.00 & - & 362.00 & 0.23 & - & 0.23 & 5.36 & - & 5.36 & $\mathrm{~S}$ & - & - & - & - \\
\hline 11 & MS/9-2196 & 332.00 & 455.58 & 393.79 & 0.21 & 0.30 & 0.26 & 7.66 & 5.08 & 6.37 & $\mathrm{~S}$ & 5.78 & 10.74 & 8.26 & $\mathrm{~S}$ \\
\hline 12 & K.Bahar & 1056.00 & 794.00 & 925.00 & 0.66 & 0.53 & 0.60 & 6.49 & 7.04 & 6.77 & $\mathrm{~S}$ & 11.85 & 11.26 & 11.56 & $S$ \\
\hline 13 & K.Garima & 424.00 & 399.58 & 411.79 & 0.27 & 0.27 & 0.27 & 4.95 & 3.68 & 4.32 & MR & 9.48 & 8.92 & 9.20 & $\mathrm{~S}$ \\
\hline 14 & K.Girdhari & 22.00 & 15.53 & 18.77 & 0.01 & 0.01 & 0.01 & 2.06 & 2.37 & 2.22 & $\mathrm{R}$ & 2.43 & 2.40 & 2.42 & $\mathrm{R}$ \\
\hline 15 & K Shailja & 135.00 & 212.42 & 173.71 & 0.09 & 0.14 & 0.12 & 4.61 & 4.53 & 4.57 & MR & 3.16 & 5.12 & 4.14 & MR \\
\hline $\begin{array}{c}\text { CD } \\
(0.05)\end{array}$ & & & & & & & & 0.69 & 1.17 & & & 1.85 & 2.19 & & \\
\hline
\end{tabular}

*AUDPC -Area under Disease Progress Curve *rAUDPC-Relative Area under Disease Progress Curve

Grading for detached leaf method: Lesion area $\left(\mathrm{cm}^{2}\right)$ Up to 1.0- Highly resistant (HR); 1.1 to 2.5- Resistant (R); 2.51-5.0- Moderately resistant; (MR) > 5.0 Susceptible (S). Grading for tuber slice method: Lesion area $\left(\mathrm{cm}^{2}\right)$ Up to 1.0- Highly resistant (HR); 1.1 to 2.5- Resistant (R); 2.51-6.0- Moderately resistant (MR) > 6.0 -Susceptible (S). - : Observation not recorded 
Table.2 Foliar and tuber resistance of advanced stage hybrids in set 2 during 2013-2015

\begin{tabular}{|c|c|c|c|c|c|c|c|c|c|c|c|c|c|c|c|}
\hline \multirow[t]{3}{*}{ S.N. } & \multirow[t]{3}{*}{ Hybrids } & \multicolumn{6}{|c|}{ Foliage resistance in field } & \multicolumn{4}{|c|}{ Foliage resistance in Lab } & \multicolumn{4}{|c|}{ Tuber resistance in Lab } \\
\hline & & \multicolumn{2}{|c|}{ *AUDPC } & \multirow[t]{2}{*}{ Mean } & \multicolumn{2}{|c|}{ *rAUDPC } & \multirow[t]{2}{*}{ Mean } & \multicolumn{2}{|c|}{$\begin{array}{c}\text { Detached leaf lesion } \\
\operatorname{area}\left(\mathrm{cm}^{2}\right)\end{array}$} & \multirow[t]{2}{*}{ Mean } & \multirow[t]{2}{*}{ Grade } & \multicolumn{2}{|c|}{$\begin{array}{c}\text { Tuber slice lesion } \\
\text { area }\left(\mathrm{cm}^{2}\right)\end{array}$} & \multirow[t]{2}{*}{ Mean } & \multirow[t]{2}{*}{ Grade } \\
\hline & & 2013-14 & 2014-15 & & 2013-14 & 2014-15 & & 2013-14 & 2014-15 & & & 2013-14 & 2014-15 & & \\
\hline 1 & MS/10-885 & 79.75 & 71.17 & 75.46 & 0.05 & 0.04 & 0.05 & 5.35 & 5.50 & 5.43 & $\mathrm{~S}$ & 8.53 & 10.55 & 9.54 & $\mathrm{~S}$ \\
\hline$\overline{2}$ & MS/10-927 & 268.50 & 312.60 & 290.55 & 0.18 & 0.20 & 0.19 & 2.47 & 2.59 & 2.53 & MR & 11.58 & 7.74 & 9.66 & $\mathrm{~S}$ \\
\hline 3 & MS/10-940 & 198.00 & 223.27 & 210.64 & 0.13 & 0.14 & 0.14 & 1.43 & 1.90 & 1.67 & $\mathrm{R}$ & 8.71 & 11.65 & 10.18 & $\mathrm{~S}$ \\
\hline 4 & MS/10-966 & 66.75 & 87.87 & 77.31 & 0.05 & 0.06 & 0.06 & 4.05 & 7.07 & 5.56 & $\mathrm{~S}$ & 10.75 & 10.84 & 10.80 & $\mathrm{~S}$ \\
\hline 5 & MS/10-1529 & 423.75 & 227.97 & 325.86 & 0.28 & 0.14 & 0.21 & 4.00 & 5.93 & 4.97 & MR & 10.66 & 7.08 & 8.87 & $\mathrm{~S}$ \\
\hline$\overline{6}$ & MCIP/09-01 & 500.50 & 164.67 & 332.59 & 0.33 & 0.10 & 0.22 & 3.52 & 2.75 & 3.14 & MR & 12.56 & 11.93 & 12.25 & $\mathrm{~S}$ \\
\hline 7 & MCIP/09-11 & 274.67 & 245.83 & 260.25 & 0.18 & 0.15 & 0.17 & 1.55 & 3.30 & 2.43 & $\mathrm{R}$ & 9.66 & 9.59 & 9.63 & $\mathrm{~S}$ \\
\hline 8 & MCIP/9-12 & 325.08 & 270.33 & 297.71 & 0.22 & 0.17 & 0.20 & 2.01 & 2.50 & 2.26 & $\mathrm{R}$ & 6.32 & 6.59 & 6.46 & $\mathrm{~S}$ \\
\hline 9 & MP/06-39 & 350.25 & 228.50 & 289.38 & 0.23 & 0.14 & 0.19 & 2.93 & 2.98 & 2.96 & MR & - & 2.29 & 2.29 & $\mathrm{R}$ \\
\hline 10 & HT/10-2505 & - & 179.90 & 179.90 & - & 0.11 & 0.11 & - & 4.00 & 4.00 & MR & - & 1.32 & 1.32 & $\mathrm{R}$ \\
\hline 11 & MP/07-214 & - & 13.00 & 13.00 & - & 0.01 & 0.01 & - & 3.77 & 3.77 & MR & - & 6.48 & 6.48 & $\mathrm{~S}$ \\
\hline 12 & K.Bahar & 794.00 & 704.67 & 749.34 & 0.53 & 0.44 & 0.49 & 7.04 & 7.34 & 7.19 & $\mathrm{~S}$ & 11.26 & 8.41 & 9.84 & $\mathrm{~S}$ \\
\hline 13 & K.Garima & 399.58 & 257.70 & 328.64 & 0.27 & 0.16 & 0.22 & 3.68 & 4.55 & 4.12 & MR & 8.92 & 10.14 & 9.53 & S \\
\hline 14 & K.Girdhari & 15.53 & 12.43 & 13.98 & 0.01 & 0.01 & 0.01 & 2.37 & 2.50 & 2.44 & $\mathrm{R}$ & 2.40 & 3.58 & 2.99 & MR \\
\hline 15 & K. Shailja & 212.42 & 44.57 & 128.50 & 0.14 & 0.03 & 0.09 & 4.53 & 4.16 & 4.35 & MR & 5.12 & 2.90 & 4.01 & MR \\
\hline $\begin{array}{c}\text { CD } \\
(0.05)\end{array}$ & & & & & & & & 1.12 & 1.07 & & & 1.44 & 2.29 & & \\
\hline
\end{tabular}

*AUDPC - Area under Disease Progress Curve *rAUDPC-Relative Area under Disease Progress Curve

Grading for detached leaf method: Lesion area $\left(\mathrm{cm}^{2}\right)$ Up to 1.0- Highly resistant (HR); 1.1 to 2.5- Resistant (R); 2.51-5.0- Moderately resistant; $(\mathrm{MR})>5.0$ Susceptible (S). Grading for tuber slice method: Lesion area $\left(\mathrm{cm}^{2}\right)$ up to 1.0- Highly resistant (HR); 1.1 to 2.5- Resistant (R); 2.51-6.0- Moderately resistant $(\mathrm{MR})>6.0$-Susceptible (S). - : Observation not recorded 
Table.3 Co-relation between different parameters for evaluation of late blight resistance

\begin{tabular}{|l|l|l|}
\multicolumn{1}{c|}{ Measures } & \multicolumn{2}{c|}{ Correlation coefficient } \\
\cline { 2 - 3 } & set 1(2012-14) & Set 2 (2013-15) \\
\hline AUDPC vs rAUDPC & $1.00^{*} * *$ & $1.00^{*} * *$ \\
\hline AUDPC vs detached leaf & 0.45 & 0.34 \\
\hline AUDPC vs tuber slice & $0.53^{*}$ & 0.32 \\
\hline Detached leaf vs tuber slice & $0.54 *$ & 0.19 \\
\hline
\end{tabular}

$* \mathrm{P}<0.05, * * \mathrm{P}<0.01$

Tuber resistance in lab with tuber slice method

Late blight pathogen ( $P$. infestans) perpetuates from one season to another mainly through infected tubers (Bhattacharyya et al., 1990). However, wherever both mating types (A1\& A2) are exists, they may survive in the form of oospores and can initiate infection. The infected tubers are sole source for spreading of the disease in the new areas where disease has not been reported yet.

Therefore, late blight resistance in tuber becomes an important attributes for screening of potato genotypes for tuber resistance. Late blight screening based on tuber slice method in set 1 , revealed that none of the hybrids was highly resistant and resistant; however, three advanced hybrids MS/8-861, MS/9-912 and MP/04-816 along with control cv. Kufri Shailja with lesion area between 2.51 to 6.0 $\mathrm{cm}^{2}$ were moderately resistant. Remaining 6 advanced hybrids along with control cv. Kufri Bahar with lesion area above $6.0 \mathrm{~cm}^{2}$ were found susceptible to late blight in tubers (Table 1).

Similarly in set 2, two advanced hybrids HT/10-2505 and MP/06-39 were resistant with lesion area between 1.1 to $2.5 \mathrm{~cm}^{2}$. Remaining 9 advanced hybrids along with control cv. Kufri Bahar with lesion area above $6.0 \mathrm{~cm}^{2}$ were found susceptible to late blight in tubers (Table 2).

\section{Co-relation between foliar and tuber resistance}

Co-relation coefficient between AUDPC and rAUDPC was high (1.00) and statistically significant in both the set 1 (2012-14) and set 2 (2013-15). It may be due to rAUDPC is highly correlated to the AUDPC. Co-relation coefficient between AUDPC and detached leaf was low 0.45 and 0.34 and statistically non-significant in set 1 and set 2 respectively. Co-relation coefficient between AUDPC and tuber resistance was 0.53 (statistically significant at $\mathrm{P}>0.05$ ) and 0.32 (statistically non-significant at $\mathrm{P}>0.01$ and $\mathrm{P}>0.05$ ) in set 1 and set 2 respectively. Similarly, co-relation coefficient between detached leaf and tuber resistance was 0.54 (statistically significant at $\mathrm{P}>0.05$ ) and 0.19 (statistically non-significant at $\mathrm{P}>0.01$ and $\mathrm{P}>0.05$ ) in set 1 and set 2 respectively (Table 3 ). At present study, foliar resistance (AUDPC \& detached leaf) and tuber resistance (tuber slice) was correlated in set1 while it was not correlated in set 2 . It may be due to diverse set of advanced hybrids. Various workers have also reported that the expression of resistance in tubers and leaves is not closely related (Schick and Hopfe, 1962; Singh, 2002 and Lal et al., 2013). However, Portal et al., (2017) reported that some of potato clones demonstrating high stable partial tuber resistance to $P$. infestans at Washington and Wisconsin had also demonstrated high foliar to moderate foliar resistance in previous field or greenhouse trials. 
In conclusion, the foliage resistance, tested under laboratory condition using detached leaf test and field condition did not establish close relationship. The expression of late blight in foliage and tuber were not closely related. The hybrids namely MS/9-723, MS/10-885, MS/10-966, MP/04-578 and MP/07-214 possessed high level of foliar resistance to late blight and two hybrids MP/06-39 \& HT/10-2505 possessed high level of resistance to tuber. Advanced hybrids viz., MS/9-2196, MS/10-1529, MP/06-39 and MP/04-578 are in multi-location evaluation trials under All India Coordinated Research Project on Potato (AICRP-P). After successful evaluations some of the hybrids may become popular variety in coming years. Moreover, some advanced hybrids with late blight resistance can be used as a parent for further breeding programme for late blight management as well as enhancing the potato production in India.

\section{Acknowledgment}

The Authors are grateful to Director ICARCentral Potato Research Institute, Shimla for providing facilities under Institute project (Nos: P1-2010/2-IPR-F30/0210).

\section{References}

Agrios, G.N. 2006. Plant Pathology. Fifth edition, Elsevier Academic Press: 903p.

Bhattacharyya, S.K., Singh, B.P., Sharma, V.C., Bombawale, O.M., Arora, R.K., and Singh, P.H. 1990. Mode of survival and source of primary inoculums of late blight. Intern. J. Tropical Pl. Disease. 8, 78-88.

Dorrance, A. E., and Inglis, D. A. 1997. Assessment of greenhouse and laboratory screening methods for evaluating potato foliage for resistance to late blight. Plant Dis., 81, 1206-1213.
Henfling, J.W. 1987. Late blight of potato: Phytophthora infestans. Technical Information Bulletin 4 (second edition revised) CIP, Lima Peru. 22 p.

Hu, CH., Perez, F.G., Donahoo, R., Mcleod, A., Myers, K., Ivors, K., Secor, G., Roberts, P.D., Deahl, K.L., Fry, W.E., and Ristaino, J. B. 2012. Recent genotypes of Phytopthora infestans in eastern United States reveal clonal populations and a of mefenoxam sensitivity. Plant Dis., 96, 1323-1330.

Johnson, D.A., Cummings T.F., Hamm, P.B. 2000. Cost of fungicides used to manage potato late blight in the Columbia Basin: 1996 to 1998. Plant Dis., 84: 399-402.

Kaushik, S.K., Bhardwaj, V., Singh, P.H., and Singh, B.P. 2007. Evaluation of potato germplasm for adaptability and resistance to late blight. Potato J., 34, 43-44.

Knutson, K.W.1962. Studies on the nature of field resistance of the potato to late blight. Amm. Potato J., 39,151-61.

Lal, M., Luthra, S. K., Singh, B. P., and Yadav, S. 2013. Screening of potato genotypes for late blight. Potato J., 40, 80-83.

Lal, M., Arora, R. K., Maheshwari, U., Rawal, S., and Yadav, S. 2014. Impact of late blight occurrence on potato productivity during 2013-14. Int J Agric Stat Sci., 12, 187-192.

Perez, W and Forbes, G. 2010. Potato late blight (Technical Mannual), CIP Publication. 38p.

Porter, L D., Brown C. R., Jansky, S. H., Johnson, D. A., Dung, J. K. S. 2017. Tuber resistance and slow-rotting characteristics of potato clones associated with the Solanaceae Coordinated Agricultural Project to the US-24 clonal lineage of Phytophthora infestans. Am. J. Potato Res. 94:160172. 
Schick, R and Hopfe, A. 1962. Die zuchtung der kartoffel. In die Kartoffel. Ein Handbuch (Eds. R. Schick and M. Klinkowski), Dt. Landwirtschaftsverlag Berlin, Bd. 2, 1461-1583.

Shanner, G and Finney, R.E.1977. The effect of nitrogen fertilization on the expression of slow mildewing resistance in knox wheat. Phytopathology, 67, 1057-1066.

Simko, I Jansky., Stephenson, S., and Spooner, D.2007. Genetics of resistance to pest and diseases. In: Potato Biology and Biotechnology Advances and Perspective (Vreugdenhil, D., with Bradshaw, J. Gebhardt, C. Grover, F. Donald, KLM, Tyler, A.M. and Ross, H.A. Eds.): 117-147.

Singh, B.P, and Birhman, R.K. 1994. Laboratory estimation of field resistance of potato to late blight. J. Phytopathol., 140, 71-76.
Singh, B.P., and Bhattacharyya, S.K. 1995. Field resistance to late blight in four Indian potato cultivars. Potato Res., 38, 171-178.

Singh, P.H. 2002. Potato late blight caused by Phytophthora infestans and its management. Ph. D Thesis, Meerut College Meerut, CCS University, Meerut. 143p.

Wastie, R.L.1991. Breeding for resistance. In Advances in Plant Pathology, vol.7 Phytophthora infestans, the cause of late blight of potato, (Eds. DS. Ingram and PH Williams). London, Academic Press: 193-224.

Yadav, S., Lal, M., Singh, B. P., Kaushik, S. K., and Sharma, S. 2016. Evaluation of fungicides against Phytophthora infestans at elevated temperature. Potato J., 43, 98-102.

\section{How to cite this article:}

Mehi Lal, S.K. Luthra, V.K. Gupta and Saurabh Yadav. 2018. Evaluation of Potato Genotypes for Foliar and Tuber Resistance against Phytophthora infestans Causing Late Blight of Potato under Subtropical Plains of India. Int.J.Curr.Microbiol.App.Sci. 7(03): 1234-1242. doi: https://doi.org/10.20546/ijcmas.2018.703.146 